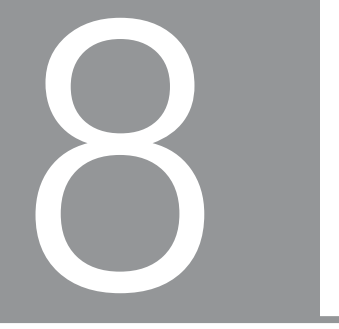

\title{
TRANS-DISCIPLINARITY AND \\ CURRICULUM SPACE IN \\ HEALTH SCIENCES EDUCATION \\ MASTER'S PROGRAMMES
}

Eli Bitzer

\section{INTRODUCTION}

The level of complexity of modern-day challenges demands a wider approach than discipline-specific measures can provide (Max-Neef 2005). These measures no longer suffice when they involve major environmental, human and social challenges. Also, relatively minor challenges such as emerging health issues, how to provide students with powerful learning opportunities and how to facilitate learning in particular social and institutional contexts are difficult to solve at the disciplinary level. Most of these challenges require trans-disciplinary approaches. Ironically, many higher education institutions still maintain mono-disciplinary courses and programmes and expect of students to do the transfer and integration of knowledge among disciplines or fields of study themselves. Moreover, the situation is not solved by creating teams of 'specialists' to address complex problems. An accumulation of visions or insights might emerge from each participating discipline, but an integrating synthesis is not achieved through the accumulation of 'different brains'. Integration and synthesis rather seem to be more productive 'within each of the brains' (Max-Neef 2005:5) and thus higher education programmes need to be oriented in ways that make trans-disciplinary knowledge possible.

In this chapter the concepts of 'trans-disciplinarity' and 'curriculum space' are discussed in the context of a cross-faculty coursework and research master's programme where these concepts are seen as being represented by the possibilities and realities of curriculum integration (Nowotny 2006) as well as by the problem-solving characteristics of the curriculum in question.

\section{Conceptual framework}

The differences among mono-disciplinarity, multi-disciplinarity, pluri-disciplinarity, inter-disciplinarity and trans-disciplinarity lie in the amount of association and integration of disciplinary knowledge (Naiman 1999; Metz 2001; Max-Neef 2005; Parker 2008). For instance, 'pure' disciplinarity is about mono-disciplinarity, which 
represents subject specialisation in isolation. A student may, for instance, study one discipline or subject without the need for knowledge about other disciplines or subjects. This implies that disciplinary knowledge is seen as only horizontally connected (i.e. next to one another without necessarily relating to one another). In the case of multidisciplinarity, a programme of study might involve more than one discipline without making connections between them, or where multi-disciplinary teams of researchers might carry out their analyses of one or more problems separately without any co-operation, integration or synthesis. Pluri-disciplinarity, on the other hand, implies co-operation between disciplines without coordination, but where the study of each one of the disciplines plays a part and reinforces the understanding of the others (MaxNeef 2005; Parker 2008).

The concept of inter-disciplinarity is organised at more than one hierarchical level (Max-Neef 2005). The coordination is between at least two and sometimes three or four levels of knowledge where the lower level is presented as empirical knowledge, the next level as inter-disciplinary purposive or pragmatic knowledge, the third level as inter-disciplinary normative knowledge and the fourth level as inter-disciplinary or values knowledge. This implies that the purpose or aim of each level of knowledge is defined by the next level of knowledge. For instance, a field of theory and practice such as medicine or health sciences defines the purpose of biology, chemistry and psychology and so forth within a particular curriculum. It thus seems clear that there can be no mention of inter-disciplinarity without clearly defining knowledge at a next hierarchical level.

This much simplified explanation of inter-disciplinarity sets the framework for explaining the phenomenon of trans-disciplinarity. Trans-disciplinarity is the result of coordination between all hierarchical levels of knowledge which needs to be defined in a completely different way (Max-Neef 2005). Figure 8.1 shows that the disciplines at the base of the pyramid describe the world as it is or as it is observed through, for example, disciplines such as physics, chemistry, geology and others.

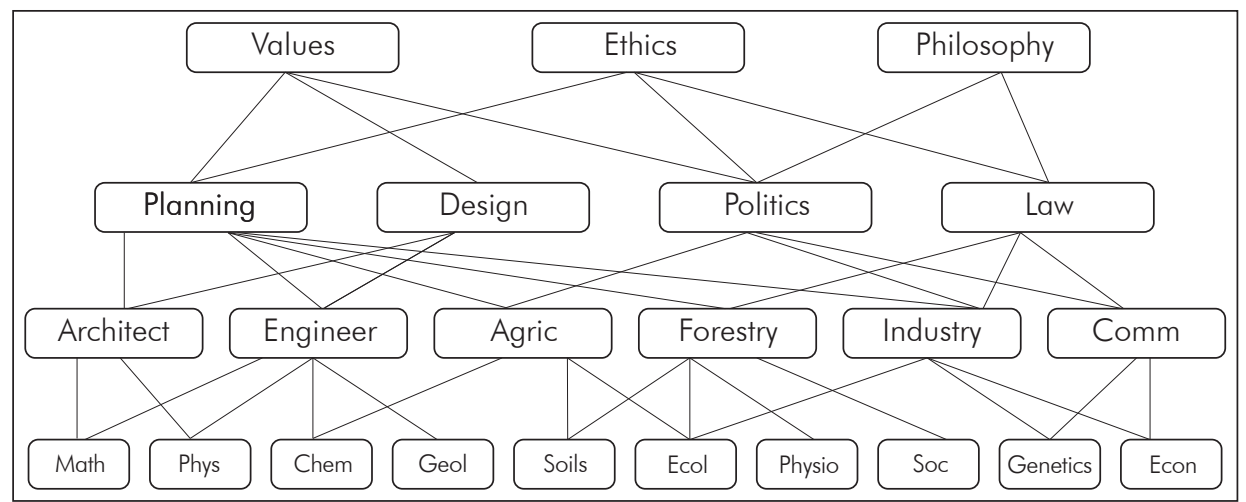

FIGURE 8.1 Examples of trans-disciplinarity in curricula 
To explain this 'hierarchy of knowledge' the following examples might be offered: The lowest level asks and answers the question: What exists? and the organising language is that of disciplinary logic or 'the disciplines'. The next level is mainly composed of technological (or applied) fields of knowledge and asks and answers the question (stemming from the empirical or disciplinary level): What are we capable of doing? The organising language is cybernetics that emphasises only the mechanical properties of nature and society and might be represented by fields of knowledge such as architecture, engineering, agriculture and others (Max-Neef 2005).

The normative (third) level asks and answers the question: What is it we want to do? An example may be the application of environmental impact assessments. The organising language at this level mostly has to do with conceptual organisation, which might be represented by areas of study such as planning, design, politics, law and others. At the (fourth) value level the prime question is: What should we do? or How should we do what we want to do? It goes beyond the present and the immediate, while its organising language should be some kind of 'deep ecology' that culminates in broad fields such as value studies, ethics and philosophy (Max-Neef 2005:9).

In most instances universities do not support trans-disciplinarity easily, particularly at the undergraduate level because academic units and programmes are mostly organised around isolated disciplines, making it virtually impossible to change traditional structures radically. Furthermore, the internal resistance to change may become insurmountable because of struggles over academic prestige and related issues. In an epistemological sense, Max-Neef (2005:15) refers to 'weak trans-disciplinarity' as a practical way of tackling problems in a more systematic way. This is helpful, but not sufficient, as 'strong disciplinarity' is obviously needed to extend the curriculum into different levels of reality.

Linked to trans-disciplinarity, but not necessarily so, is the principle of knowledge relation. Relating one body of knowledge to other bodies of knowledge in the formation of curricula is the focus of Max-Neef's (2005) argument. Two important relational factors are (1) the degree of integration between different knowledge domains and (2) progression within the domain itself. Therefore, a curriculum may be understood as strongly or weakly classified and as strongly or weakly framed (Nowotny 2006). A strongly classified curriculum is defined as one that has clearly delineated domains of knowledge with strong boundaries between them. Conversely, a weakly classified curriculum is understood as having weak boundaries between the different knowledge domains. While a strongly framed curriculum is defined as a programme of study in which students have limited control over the selection of content and the way in which it is organised in respect of the pedagogical relationship, a weakly framed curriculum is characterised by greater control by students over content, organisation and pacing (see in particular Bernstein 1996, 2000).

To summarise the two main positions relevant to this chapter, namely strong and weak trans-disciplinarity (Max-Neef 2005) and classified and framed curriculum spaces 
(Bernstein 1990, 1996,2000), Table 8.1 portrays a conceptual framework used for a small-scale investigation into a postgraduate health sciences education curriculum that served as the unit of analysis in this study.

TABLE 8.1 A conceptual framework of key operational concepts

\begin{tabular}{ll|l|}
$\begin{array}{l}\text { Weak/strong trans- } \\
\text { disciplinarity (T-D) } \\
\text { (e.g. Max-Neef 2005) }\end{array}$ & $\begin{array}{l}\text { Disciplines prominent in the } \\
\text { curriculum are unrelated and } \\
\text { may not be able to solve complex } \\
\text { problems. }\end{array}$ & $\begin{array}{l}\text { Wisciplines are integrated in the } \\
\text { curriculum and geared to solve } \\
\text { complex problems. }\end{array}$ \\
\hline $\begin{array}{l}\text { Curriculum space } \\
\text { (e.g. Bernstein 1990, } \\
\text { 1996, 2000) }\end{array}$ & $\begin{array}{l}\text { Strongly and tightly classified } \\
\text { knowledge domains are well } \\
\text { delineated and boundaries are } \\
\text { strong and tight (impermeable). }\end{array}$ & $\begin{array}{l}\text { 'Classified' space } \\
\text { knowledge domains are not well } \\
\text { delineated and boundaries are weak } \\
\text { and loose (permeable). }\end{array}$ \\
\hline $\begin{array}{l}\text { Strongly and tightly framed } \\
\text { knowledge domains are those } \\
\text { where teachers and students } \\
\text { have little control over content, } \\
\text { organisation and pacing. }\end{array}$ & $\begin{array}{l}\text { 'Framed' space } \\
\text { knowledge domains are those where } \\
\text { teachers and students have greater } \\
\text { control over content, organisation } \\
\text { and pacing. }\end{array}$ \\
\hline
\end{tabular}

Before discussing the application of this conceptual frame, the context and characteristics of the programme and the module in question need some explanation.

\section{CONTEXT}

The programme aims and content of the MPhil in Health Sciences Education (HSE) at Stellenbosch University are shown in Table 8.2. The total study time accounts roughly for 1800 hours of teaching, learning and assessment (mainly shorter assignments) as well as a larger research component of 30\%. The first student intake in 2008 comprised seven students and participation trebled to 21 students in 2009 and tapered off to 16 students in 2010 .

The unit of analysis in this study was the module or study block 'Curriculum Analysis in Health Sciences Education' which is offered in the second year of study. Three other academic staff members (two from Stellenbosch University and one from abroad) are part of the module team. Seven students in their second year enrolled for the module which comprises one full day of class contact and six weeks of electronically mediated learning, culminating in an assignment that represents the summative assessment task for the module. Six of the seven students who participated in the module between February and April 2010 passed the assignment. The students are all professionally qualified HSE practitioners and all have senior teaching positions in their respective fields in health sciences education. 
TABLE 8.2 Outline of the MPhil (Health Sciences Education) programme at Stellenbosch University

\section{Programme aims}

- Promote excellence in education, research and community service in the field of HSE.

- Facilitate research and academic reflection to contribute to the body of knowledge in HSE.

- Promote a rich learning environment, including trans-disciplinarity and international participation and inputs.

- Develop HSE leaders who can contribute to evidence-based practices in HSE.

\begin{tabular}{|l|c|}
\hline Modules (Year 1) & Credit* \\
\hline Contextualising HSE & 5 \\
\hline Learning in HSE & 15 \\
\hline Educational research for change in HSE & 10 \\
\hline Research assignment (conceptualisation and planning) & 15 \\
\hline Facilitating learning in HSE & 15 \\
\hline Research methodology & 10 \\
\hline Elective 1: Skills development in HSE & 10 \\
\hline Elective 2: Leadership in HSE & 10 \\
\hline Modules (Year 2) & Credits* \\
\hline Learning and teaching for primary health care & 15 \\
\hline Curriculum analysis in HSE & 15 \\
\hline Research assignment & 45 \\
\hline Assessment in HSE & 15 \\
\hline Elective 3: Personal and professional development & 10 \\
\hline Elective 4: e-Learning & 10 \\
\hline Total credits & 180 \\
\hline
\end{tabular}

* One credit equals approximately 10 hours of teaching, learning and assessment.

\section{METHOD}

The limited survey employed qualitative methodology aimed at investigating the experiences of three tutors and six MPhil (HSE) students in 2010. In-depth e-mail conversation techniques were employed for data collection and involved exchanges over a period of more than a month. This way of data gathering proved to be appropriate due to its flexible nature and interactivity. Two sets of key questions (one set for tutors and one for students) guided conversations and probes were used where necessary and appropriate.

\section{Questions to staff}

Tutors were asked to respond to the following two questions based on their experience of (a) the programme at that stage and (b) more specifically, their experience of the completed module 'Curriculum Analysis in HSE': 
1. (a) Would you describe the MPhil (HSE) programme in total as of a weak or strong trans-disciplinary nature (i.e. disciplinary knowledge in the programme is not well integrated or well integrated)? Why?

(b) Would you describe the module 'Curriculum Analysis in HSE' as of a strong or a weak trans-disciplinary nature? Why?

2. (a) Would you describe the MPhil (HSE) programme in total as strongly or weakly classified and framed? Why?

(b) Would you describe the module 'Curriculum Analysis in HSE' as strongly or weakly classified and framed? Why?

\section{Questions to students}

Without providing any background information and with the aim of focusing primarily on students' perceptions and experiences of the module, the following five simplified questions were posed to the six students who had completed the module assignment successfully:

Question 1: Was the module useful to your work as an educator in Health Sciences Education? Can you briefly say why (not)?

Question 2: Did the module contain too much or too little or just the right amount of educational material (i.e. literature and inputs from Education)? Why would you say so?

Question 3: Did the module contain too much or too little or just the right amount of health sciences material (i.e. literature and inputs from Health Sciences)? Why would you say so?

Question 4: Did you feel 'boxed in' by the module in the sense that your own manoeuvrability or creativity was limited? Why would you say so?

Question 5: Do you think that the Curriculum Analysis module (a) represents an example of trans-disciplinarity or (b) is the knowledge in this module not really integrated?

Analysis of the electronically generated data was inductive, looking for trends and patterns that could yield insight into the curriculum experiences of both tutors and students. Analytical and interpretive processes were followed, firstly by familiarisation through several readings of the responses. Data was then classified into categories and themes in accordance with the questions asked, which were subsequently explored more closely and finally interpreted (Terre Blanche \& Durrheim 1999).

\section{RESULTS}

The three tutors responded in varied depth to the two questions. Tutor 1 saw the programme and the module in question as 'a hybrid, apparently not strong in transdisciplinarity'. In his view there is some tension between education as a discipline and 
health care as a separate field, although knowledge about learning and teaching are beneficial to health professions education. He emphasised that the health professions have a strong culture and 'will only accept strongly contextualised advice'. The challenge seems to make educational expertise in a programme such as the MPhil (HSE) relevant to health professionals and if it remains theoretical, or if disciplinary knowledge is not translated and integrated, it will not be seen as valuable.

Tutor 2 saw traces of trans-disciplinarity in both the programme and the module. Asked why, this tutor responded by saying that 'education as a discipline is apparently somewhat integrated into health sciences education'. Also, the programme would be unable to stand on its own if education as a discipline did not play a role in knowledge construction. This integration provides 'a wider perspective' as health education professionals do not generally have any background in educational studies. He also saw both the programme and the Curriculum Analysis module as weakly classified and framed as the 'relevant educational knowledge is not necessarily confined to health sciences education but has wider applications to other programmes and modules'. According to this tutor, students have ample opportunities to explore and apply the gained knowledge freely within their own contexts.

Tutor 3 regarded the MPhil (HSE) programme (the programmatic context for the Curriculum Analysis module) as characterised by signs of strong trans-disciplinarity, 'especially in modules where the focus is on generic principles related to education in a broader sense'. He felt that in some of the modules, however, the trans-disciplinarity is bound to be weaker as they focus on aspects that are unique to Health Sciences as a knowledge field (e.g. modules such as Learning and Teaching for Primary Care). Another example of weaker trans-disciplinarity might be within modules such as Assessment in HSE where specific issues of the assessment of clinical skills are dealt with. Conversely, the module Curriculum Analysis in HSE was seen as having strong trans-disciplinarity, except when dealing with the analysis of the clinical training component of the HSE programme. This tutor also saw both the MPhil programme and the Curriculum Analysis module as being generally weakly classified, but strongly framed, since while tutors have a fair amount of control over content, students do not (except in their research assignments). In his view students have little control over organisation and pacing as the programme committee takes the major curriculum decisions.

Five of the six students who completed the module successfully replied to the questions posed (see Table 8.3). 
TABLE 8.3 Summarised student responses to questions on trans-disciplinarity and curriculum space in one MPhil (HSE) module

\begin{tabular}{|c|c|c|c|c|c|}
\hline & Question 1 & Question 2 & Question 3 & Question 4 & Question 5 \\
\hline $\begin{array}{l}\frac{t}{0} \\
\frac{0}{0} \\
0 \\
0 \\
0 \\
0\end{array}$ & $\begin{array}{l}\text { Was the module } \\
\text { useful to your } \\
\text { work as an } \\
\text { educator in } \\
\text { Health Sciences } \\
\text { Education? Can } \\
\text { you briefly say } \\
\text { why (not)? }\end{array}$ & $\begin{array}{l}\text { Did the module } \\
\text { contain too much } \\
\text { or too little or just } \\
\text { the right amount } \\
\text { of educational } \\
\text { material (i.e. } \\
\text { literature and } \\
\text { inputs from } \\
\text { Education)? Why } \\
\text { would you say so? }\end{array}$ & $\begin{array}{l}\text { Did the module } \\
\text { contain too much } \\
\text { or too little or } \\
\text { just the right } \\
\text { amount of health } \\
\text { sciences material } \\
\text { (i.e. literature } \\
\text { and inputs from } \\
\text { Health Sciences)? } \\
\text { Why would you } \\
\text { say so? }\end{array}$ & $\begin{array}{l}\text { Did you feel } \\
\text { 'boxed in' by } \\
\text { the module } \\
\text { in the sense } \\
\text { that your own } \\
\text { manoeuvrability } \\
\text { or creativity was } \\
\text { limited? Why } \\
\text { would you say } \\
\text { so? }\end{array}$ & $\begin{array}{l}\text { Do you think that } \\
\text { the Curriculum } \\
\text { Analysis module } \\
\text { (a) represents an } \\
\text { example of trans- } \\
\text { disciplinarity, } \\
\text { or (b) is the } \\
\text { knowledge } \\
\text { integrated? }\end{array}$ \\
\hline 1 & Yes & Right amount & Right amount & $\begin{array}{l}\text { Yes, quite } \\
\text { 'boxed in' }\end{array}$ & Not integrated \\
\hline 2 & Yes & Right amount & Right amount & $\begin{array}{c}\text { No, not limiting } \\
\text { at all }\end{array}$ & Integrated \\
\hline 3 & $\begin{array}{l}\text { Still limited } \\
\text { knowledge }\end{array}$ & Too much & Right balance & Struggled & Integrated \\
\hline 4 & Yes & Right amount & Right amount & No & Integrated \\
\hline 5 & Yes & Too much & Right amount & No & Not integrated \\
\hline
\end{tabular}

Table 8.3 shows that, in response to question 1, all but one student respondent considered the module as being useful for their educational practices. However, another student (Respondent 3) reported that her knowledge was still limited. As an example of a positive response, Student 1 had the following to say about the usefulness of the module:
Yes, the module was useful. Curriculum analysis was always a 'fuzzy' area for me, and I did not have the capacity to understand why a curriculum had to be analysed. By completing this module I became aware of the importance of any 'curriculum analysis event', and the skills that I learnt in the process will be transferable to any academic environment, inside and outside of health sciences. I am proud that I could analyse the MB ChB curriculum as part of the modular requirements and in the short time provided.

On whether the module contained too much education or health sciences content (Q2 and Q3), the students' responses varied. While three students reported that the education material was just right for them, two said it was 'too much'. For instance, Student 2, who said that the educational knowledge was too much, had the following explanation:

I do realise that the standard for this module is at the master's level. However,

I do not feel that I have mastered the educational content. For me personally, I would have managed two or three smaller assignments better. The content was fine, but overwhelming when it had to be integrated into one assignment. 
In the case of Student 2 it appears that the problem was not so much with the education content of the module, but more with how the assignment (assessment) was structured that posed a problem.

The last question (Q5) dealt with perspectives on trans-disciplinarity and integration of disciplines. Table 8.3 shows that three respondents considered the module to be 'integrated' as far as education and health sciences are concerned, but two did not see much integration. Student 5 explained the lack of integration and weak transdisciplinarity in the following way:

I see the module as only having elements of both fields, which are not really integrated. I am not convinced that the module can represent trans-disciplinarity, since I think that the MPhil programme as a whole should be able to do that before anyone can claim that a specific module is able to do so. Part of the reason I wanted to study health sciences education was to learn how to contribute to the development of building a bridge between general educationalists and health science educationalists.

It seems obvious that in this particular case the student did not see integration of knowledge or trans-disciplinarity as emerging from the module or the programme.

\section{DISCUSSION}

The findings from this limited survey in one programme and study unit have shown that tutors' responses varied between observing 'traces' of trans-disciplinarity to a 'hybrid' model (meaning a mix between weak and strong trans-disciplinarity) to 'strong' trans-disciplinarity with exceptions. Tutors were therefore not in agreement on the reigning curriculum model, but what seems common is that content from the discipline of education is seen to provide health educators with 'wider perspectives' provided it is contextualised and relevant to the health education profession. On the issue of curriculum space (framing and classification) there also seems to be difference of opinion among tutors, with an indication of ample opportunities for students to apply educational knowledge in their respective health science contexts. Obviously the diverse opinions or 'confusion' about trans-disciplinarity, framing and classification need to be addressed through more intensified and coordinated curriculum planning and development efforts (Cary 2006; Harvey \& Knight 1996). There has to be some kind of consensus among tutors about these issues (Pugsley, Brigley \& MacDonald 2008) if the programme and module aim of optimising learning opportunities is to be realised, particularly at the postgraduate level.

From tutor and student feedback at least three conclusions might be drawn. Firstly, there are a few signs of strong trans-disciplinarity as defined by Max-Neef (2005) in both the module and the programme. Most literature sources refer to trans-disciplinarity in terms of research (Nowotny 2006; Pugsley et al 2008), but postgraduate curricula are also in the spotlight for their apparent rigidity and disciplinary focuses (Harvey \& Knight 1996; Lawrence 2004). Particularly at the master's level of studies in professional 
fields such as HSE it is assumed that students should gain a deeper understanding of social research processes and contexts to interrogate educational issues. In line with the findings of this limited survey, literature reports increasing challenges for clinicians who try to complete educational-type studies amidst their full-time professional and teaching commitments (Pugsley et al 2008). It is also assumed that if health science educators do not see master's studies and the research projects they conduct as being highly relevant to their educational practices in health sciences, completion rates might be low and the satisfaction gained from these types of studies might be limited. Against this background a purposive drive towards increased trans-disciplinarity and provision of ample curriculum space makes good sense as health care problems are complex and teaching-learning situations are varied and challenging (Dillon 2008).

Secondly, in Bernstenian terms curriculum space in the module (and the programme for that matter) currently seems to be both weakly and loosely classified and weakly and loosely framed. This is a positive finding and ties in with views on the importance of intersections of epistemology, ontology, theory and research in postgraduate curricula (Dillon 2008; see in particular Barnett \& Coate 2005). The knowledge types making up the curriculum, expectations of students, the way curricula are planned and the position of research all seem to play major roles in postgraduate students' perceptions of how well they are allowed to create and utilise space in the curriculum. In this study the findings from students' responses in particular pointed to what Bernstein (1990:48) has termed 'valid forms of knowledge and pedagogy' in the sense that in general, most students perceived the curriculum in question as being relatively open and non-constraining regarding their educational practices in the health sciences. Although there might not be many signs of a well-integrated curriculum (i.e. closely integrated among education, health sciences and higher education in this case), the current disciplinary boundaries are not overtly tight and the fact that the curriculum planners and lecturers are working jointly in a team to point out overlapping concepts, problems and themes proves to be encouraging.

Thirdly, it seems that trans-disciplinarity and opening up curriculum space in HSE are still largely underexplored and underdeveloped. It has been pointed out (Nowotny 2006) that relevant (or mode 2) knowledge types (Gibbons 2005) imply problembased approaches, heterogeneity in participants and strong integration of knowledge. Unfortunately, as is the case in most universities and programmes, disciplinary structures and hierarchical forms of organisation still largely prevail. In the case of the module in focus and the MPhil (HSE) programme in general, the tutors, who also serve as the curriculum planners, represent different disciplines and different academic units in the institution in question but think in similar ways about the aims and outcomes of the programme. This seems to be a positive development in realising stronger future possibility of trans-disciplinarity.

In conclusion: Key questions about education need to be understood and addressed by way of innovative concepts and methods. This stems from the fact that the capacity 
of educators to deal with these questions is insufficient even though many are convinced that formal studies such as master's programmes will provide them with the 'right' answers. However, if these programmes are not decompartmentalised or 'de-disciplinised' and do not increasingly deal with the diverse nature of the social contexts in which people live and teach, the answers will remain superficial and only of academic concern. In order to deal with these limitations, knowledge frameworks and thought need to be revised. Moreover, efforts towards trans-disciplinarity and increased curriculum space could be part of this solution and further inquiry into other cross-faculty postgraduate programmes might contribute to a productive debate.

\section{REFERENCES}

Barnett R \& Coate K. 2005. Engaging the curriculum in higher education. Maidenhead: Society for Research into Higher Education \& Open University Press.

Bernstein B. 1990. Class, codes and control: The structuring of pedagogic discourse. London: Routledge \& Kegan Paul.

Bernstein B. 1996. Pedagogy, symbolic control and identity: Theory, research and critique. London: Taylor and Francis.

Bernstein B. 2000. Pedagogy, symbolic control and identity: Theory, research and critique. Revised Edition. London: Taylor and Francis.

Cary LJ. 2006. Curriculum spaces. Frankfurt: Peter Lang.

Dillon P. 2008. A pedagogy of connection and boundary crossings: Methodological and epistemological transactions in working across and between disciplines. Innovations in Education and Teaching International, 45(3):255-262.

Gibbons M. 2005. Higher education relevance in the 21 st century. Washington, DC: The World Bank.

Harvey L \& Knight P. 1996. Transforming higher education. Buckingham: Open University Press.

Lawrence RJ. 2004. Futures of transdisciplinarity. Futures, 36:397-405.

Max-Neef MA. 2005. Foundations of transdisciplinarity. Ecological Economics, 53:5-16.

Metz MH. 2001. Intellectual border crossing in graduate education: A report from the field. Educational Researcher, 30(5):12-18.

Naiman RJ. 1999. A perspective on interdisciplinary science. Ecosystems, 2:292-295.

Nowotny H. 2006. The potential of transdisciplinarity. [Retrieved 17 June 2010] http://66.102.1.104/scholar

Parker J. 2008. Beyond disciplinarity: humanities and supercomplexity. London Review of Education, 6(3):255-266.

Pugsley L, Brigley LA \& MacDonald J. 2008. Making a difference: Researching master's and doctoral research programmes in medical education. Medical Education, 42:157-163.

Terre Blanche M \& Durrheim K. 1999. Research in practice. Cape Town: University of Cape Town Press. 